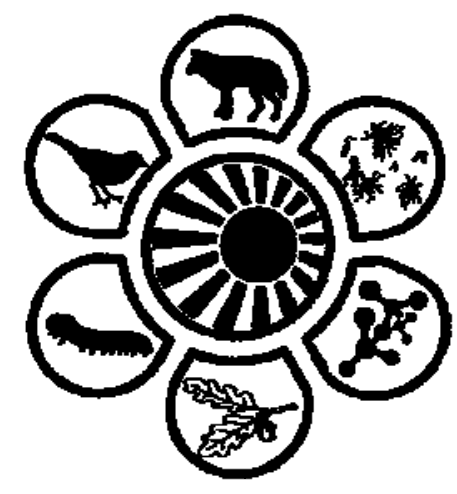

Вісник Дніпропетровського університету. Біологія, екологія.

Vìsnik Dnìpropetrovs'kogo unìversitetu. Seriâ Bìologiâ, ekologiâ

Visnyk of Dnipropetrovsk University. Biology, ecology.

Vìsn. Dnìpropetr. Unìv. Ser. Bìol. Ekol. 2015. 23(2), 210-215.

doi: $10.15421 / 011530$

ISSN 2310-0842 print

ISSN 2312-301X online

www.ecology.dp.ua

УДК 551.468.3(262.5)

\title{
Жизненные стратегии равноногих ракообразных в условиях черноморского сообщества обрастания
}

\author{
А.Ю. Варигин \\ Институт морской биологии НАН Украины, Одесса, Украина
}

Рассмотрены характерные черты жизненных стратегий двух массовых видов равноногих ракообразных Idotea balthica basteri (Pallas, 1772) и Lekanesphaera monodi (Arcangeli, 1934), совместно обитающих в сообществе обрастания прибрежной зоны Одесского залива Черного моря. Отмечена сбалансированность межвидовых отношений изучаемых видов в данном сообществе. Их конкурентные отношения носили диффузный характер, отражающий относительно слабые по силе межвидовые взаимодействия. Экологические ниши этих видов перекрывались лишь по местообитанию. По трофическим и временным характеристикам конкуренция между ними ослаблена. Отмечена эффективность жизненных стратегий обоих видов ракообразных, что подтверждается их массовостью в сообществе обрастания Одесского залива Черного моря.

Ключевые слова: равноногие ракообразные; жизненная стратегия; экологическая ниша; сообщество обрастания

\section{Life strategies of isopods under conditions of the Black Sea fouling community}

\author{
A.Y. Varigin \\ Institute of Marine Biology of NASU, Odessa, Ukraine
}

The main features of the life strategies of mass species of isopod Idotea balthica basteri (Pallas, 1772) and Lekanesphaera monodi (Arcangeli, 1934) living in fouling communities of the coastal zone of the Odessa Bay, the Black Sea, are determined. High degree of eurybiontity of these species, allowing them to successfully resist the effects of sharp fluctuations in abiotic environmental factors in the coastal zone, is noted. Comparison of the elements of life strategies of I. balthica basteri and L. monodi in the fouling community is made. The balance of interspecific relationships of these species within the fouling community is recorded. Competitive relations of $I$. balthica basteri and L. monodi are diffuse, reflecting relatively weak in strength interspecific interactions. It is shown that the ecological niches of these species overlap only on the axis of the habitat. Food competition between them has been greatly weakened due to trophic specialization of each species, owing to the features of the functional morphology of their mouthparts. Main elements of their life cycles associated with periods of mass reproduction and migration from the coastal zone are separated in time. It is found that both species exhibit a fairly high degree of care for their offsprings. Comparison of annual biomass changeability of both species, reflecting the characteristics of their reproductive cycle in fouling communities, is made. It is shown that these species reach their maximum biomass in different seasons. We also noted their pronounced protective coloration integument of the body, which is the passive way of protection from predators. Life strategies of I. balthica basteri and L. monodi proved to be quite effective, as evidenced by their massive development in the fouling community of the Odessa Bay.

Keywords: isopods; life strategy; ecological niche; fouling community

Институт морской биологии НАНУ, ул. Пушкинская, 37, Одесса, 65011, Украина Institute of Marine Biology of NASU, Pushkinska Str., 37, Odessa, 65011, Ukraine Tel.:+38-048-725-09-18.E-mail: sealife_1@mail.ru 


\section{Введение}

Равноногие ракообразные Idotea balthica basteri (Pallas, 1772) и Lekanesphaera monodi (Arcangeli, 1934) широко распространены в заливах, эстуариях и лагунах Средиземного и Черного морей (Marzano et al., 2003; Kirkim et al., 2014; Reizopoulou et al., 2014). В некоторых районах этих морей они являются массовыми видами (Mancinelli et al., 2005; Varigin, 2014a). Эти ракообразные, как и другие животные, обитающие в прибрежной зоне морей, обладают высокой степенью эврибиотности, способны переносить значительные колебания температуры и солености воды, устойчивы к дефициту кислорода (Vetter et al., 1999; Marzano et al., 2007).

Благодаря значительному уровню эврибионтности I. balthica basteri и L. monodi одинаково успешно могут противостоять воздействию абиотических факторов среды, которые в прибрежной зоне морей подвержены значительным, а иногда и резким колебаниям. Однако внутри сообществ действуют еще и биотические факторы. Как же этим двум животным, обладающим столь высокими адаптационными возможностями, удается совместно обитать в прибрежном сообществе, не вступая в явные конкурентные отношения друг с другом? Получить ответ на этот вопрос можно, рассмотрев особенности их жизненных стратегий, реализуемых в условиях сообщества обрастания Одесского залива Черного моря.

Известно, что в процессе развития сообществ происходит отбор таких жизненных стратегий входящих в них организмов, которые наиболее адекватно соответствуют условиям их обитания, включая как абиотические, так и биотические факторы среды (Protasov, 2009). В современной экологии сформировались представления, что K-стратегия связана с отбором, направленным на общее повышение выживаемости каждого потомка, активное потребление ресурсов в конкурентных условиях уже сформировавшегося сообщества, увеличение защищенности от абиотических факторов среды, развитие совершенных механизмов регуляции численности популяции, а r-стратегия определяется отбором, направленным на увеличение скорости роста популяции в начальный период формирования сообщества за счет быстрого достижения особями половозрелости, высокой индивидуальной плодовитости, короткого жизненного цикла и способности к захвату новых местообитаний (Giljarov, 1990). Однако в реальных условиях жизни потенциал выживаемости популяций, включая способность переживать стрессовые воздействия и успешно восстанавливаться после нарушений, обеспечивается более сложным набором элементов стратегий, которые могут быть охарактеризованы целым рядом параметров и признаков (Protasov, 2009). Цель работы состояла в определении элементов жизненных стратегий I. balthica basteri и L. monodi, которые позволяют им совместно обитать и развиваться в прибрежном сообществе обрастания Одесского залива Черного моря, где эти ракообразные являются массовыми видами.

\section{Материал и методы исследований}

Материалом работы послужили пробы, отобранные на подводной поверхности берегозащитных сооружений, расположенных в прибрежной зоне Одесского залива. Пробы отбирали ежемесячно с января по декабрь 2013 г. с помощью металлической рамки, размером $20 \times 20 \mathrm{~cm}$, обтянутой мельничным газом. Содержимое каждой рамки промывали через систему почвенных сит с минимальным размером ячеи 0,5 мм. Собранных ракообразных идентифицировали, подсчитывали, определяли их половую принадлежность, измеряли длину (расстояние от переднего края головы до конца тельсона) с точностью до 0,1 мм и сырую массу (предварительно обсушив животных на фильтровальной бумаге) с точностью до 1 мг. Абсолютную плодовитость ракообразных - общее число яиц, образуемое самкой за один помет, определяли с помощью прямого подсчета яиц у каждой яйценосной самки. При описании динамики количественных параметров ракообразных использовали общепринятые показатели численности $\mathrm{N}$ (экз./ $\left.\mathrm{M}^{2}\right)$ и биомассы B $\left(\Gamma / \mathrm{M}^{2}\right)$.

\section{Результаты и их обсуждение}

Оба рассматриваемые вида, прежде всего, различаются по своим размерным характеристикам (табл.). В условиях сообщества обрастания Одесского залива максимальная длина самцов и самок I. balthica basteri составляет 18,0-18,5 и 12,0-12,6 мм, соответственно. Для L. monodi характерны более мелкие размеры. Самцы этого вида в Одесском заливе достигают максимальной длины 10,5 мм, а самки - 7,5 мм. Таким образом, как самцы, так и самки I. balthica basteri превышают по размерам L. monodi почти в 1,7 раза.

Эти два вида являются подвижными животными, способными покинуть прибрежную зону в случае наступления неблагоприятных условий, превышающих предел их толерантности. Однако уровень их подвижности различен. I. balthica basteri в течение суток могут некоторое время сидеть, крепко уцепившись за субстрат, ползать по нему или плавать в толще воды, проявляя при этом разную степень подвижности. Периоды активности I. balthica basteri связаны в основном с процессом питания. В остальное время они могут подолгу оставаться на одном месте, часто не меняя положения в течение 1,5-2,5 часа (Hmeleva, 1973). Степень подвижности молодых животных наивысшая ввиду того, что они питаются значительно чаще, чем взрослые особи. Молодь остается подвижной примерно 10 ч в сутки, тогда как для взрослых этот показатель не превышает 4 ч. Во время движения, которое осуществляется за счет усиленного биения плеоподов, тело этих ракообразных принимает обтекаемую форму. При этом форсированная скорость I. balthica basteri может достигать 16-22 cм/с (Hmeleva, 1973).

Второй изучаемый вид, L. monodi, отличается значительно меньшим уровнем подвижности по сравнению с первым. Это ракообразное не имеет обтекаемой формы и большую часть суток проводит, неподвижно сидя на субстрате или медленно ползая по нему в поисках пищи. При малейшей опасности моментально сворачивается в 
шар. Хотя в некоторых случаях, например, во время массовых миграций, L. monodi может активно плавать, передвигаясь с помощью слаженной работы конечностей (Kusakin, 1979).

Одним из важнейших элементов жизненной стратегии вида является характер его репродукционного процесса. Способность к размножению является неотъемлемым свойством живых организмов, благодаря которому обес- печивается устойчивое существование и развитие вида, поскольку продолжительность жизни отдельных его особей ограничена (Hmeleva, 1988). У изучаемых видов ракообразных в достаточной степени выражен половой диморфизм. При этом I. balthica basteri размножается в течение всего года, но наиболее интенсивно - ранней весной, a L. monodi, как моноцикличный вид, приступает к размножению только поздним летом (табл.).

Сравнительная характеристика элементов жизненных стратегий I. balthica basteri и L. monodi

Таблица

\begin{tabular}{|c|c|c|}
\hline Элементы жизненных стратегий & I. balthica basteri & L. monodi \\
\hline Уровень эврибионтности & высокий & Высокий \\
\hline Максимальная длина тела самца/самки, мм & $18,5 / 12,6$ & $10,5 / 7,5$ \\
\hline Степень подвижности & средняя & низкая \\
\hline Степень заботы о потомстве & высокая & высокая \\
\hline Соотношение полов в популяции & самок всегда больше, чем самцов & самок всегда больше, чем самцов \\
\hline Репродукционный период & в течение всего года & один раз в год \\
\hline Период, когда происходит наиболее интенсивное размножение & ранняя весна & позднее лето \\
\hline Максимальная абсолютная плодовитость, яиц/самку & 86 & 68 \\
\hline Длительность эмбриогенеза при температуре воды $20^{\circ} \mathrm{C}$, сут. & 16 & 77 \\
\hline Длина тела появляющейся на свет молоди, мм & $1,3-1,5$ & $1,3-1,4$ \\
\hline Способ питания & полифагия & полифагия \\
\hline Преимущественный способ потребления растительной пищи & $\begin{array}{c}\text { поедание частей талломов } \\
\text { макрофитов } \\
\end{array}$ & $\begin{array}{c}\text { соскабливание эпифитных } \\
\text { микроводорослей }\end{array}$ \\
\hline Покровительственная окраска & ярко выражена & ярко выражена \\
\hline $\begin{array}{l}\text { Период в году, когда происходят массовые миграции } \\
\text { из прибрежной зоны моря }\end{array}$ & конец лета - начало осени & зима \\
\hline Максимальные численность/биомасса, экз $/ \mathrm{M}^{2} / \mathrm{\Gamma} / \mathrm{M}^{2}$ & $4025 / 60,3$ & $1450 / 18,9$ \\
\hline Продолжительность жизни, месяцев & $12-14$ & $10-12$ \\
\hline
\end{tabular}

Процесс спаривания у I. balthica basteri и L. monodi в общих чертах весьма сходен. Половозрелыми эти ракообразные становятся довольно быстро. Самки I. balthica basteri при температуре воды $20{ }^{\circ} \mathrm{C}$ созревают уже через полтора месяца после появления на свет (Hmeleva, 1973). Во время спаривания самец удерживает самку под вентральным сводом своего тела и не отпускает до тех пор, пока у нее не начнется линька. Внутреннее оплодотворение происходит лишь после того, как самка сбросит свои хитиновые покровы. После оплодотворения у самок I. balthica basteri развивается наружная выводковая сумка (marsupium), сложенная из пластин, представляющих собой выросты коксальных члеников грудных ног (Kusakin, 1982). Самки L. monodi вынашивают оплодотворенные яйца и развивающиеся эмбрионы во внутренних выводковых мешочках, образованных парными впячиваниями кожных покровов на вентральной стороне их грудных отделов (Kusakin, 1979). Таким образом, оба вида проявляют довольно высокую степень заботы о потомстве.

Плодовитость, рассматриваемая как элемент жизненной стратегии вида, является основным репродуктивным показателем, определяющим воспроизводительную способность животного. От количества вышедшей из яиц жизнеспособной молоди во многом зависит процветание данного вида в конкретных условиях обитания (Hmeleva, 1988). Плодовитость изучаемых видов относительно невелика и зависит, прежде всего, от размеров самки. В условиях сообщества обрастания Одесского залива максимальная абсолютная плодовитость (общее число яиц, образуемое самкой за один помет) у I. balthica basteri составляет 86, a у L. monodi - 68 яиц (табл.).
Продолжительность эмбрионального развития у этих ракообразных зависит, прежде всего, от температуры воды. При температуре морской воды $20{ }^{\circ} \mathrm{C}$ молодь у I. balthica basteri появляется через 16 суток после оплодотворения яиц (Hmeleva, 1973). При этом длина только что отродившихся ракообразных обоих видов примерно одинакова и составляет от 1,3 до 1,5 мм (табл.). Для другого вида ракообразных, размножающегося лишь один раз в году, характерна значительно большая продолжительность эмбрионального развития, равная 77 суткам (Makkaveeva, 1974).

Способ питания как элемент жизненной стратегии вида чаще всего рассматривается через призму конкурентных межвидовых взаимоотношений. Ведь от доступности пищевых объектов зависит развитие и процветание вида в конкретных условиях обитания. И именно в этой сфере происходит соперничество между совместно обитающими видами, имеющими сходный способ питания.

У I. balthica basteri и L. monodi, как и у большинства других свободноживущих представителей отряда Isopo$\mathrm{da}$, ротовой аппарат грызущего типа, что позволяет им измельчать довольно разнообразную пищу (Kusakin, 1979). Благодаря этому рассматриваемые виды ракообразных по способу питания относятся к полифагам. Они могут потреблять различные части макрофитов, одноклеточные водоросли, детрит, псевдофекалии двустворчатых моллюсков, мелких беспозвоночных, погибших животных, а также линочные шкурки ракообразных (Hmeleva, 1973; Makkaveeva, 1974).

Обычно организмы на разных этапах онтогенеза для обеспечения оптимальной выживаемости используют различные жизненные стратегии (Protasov, 2009). Это в 
полной мере относится к рассматриваемым видам. Недавно появившиеся на свет молодые особи I. balthica basteri и L. monodi имеют мягкие покровы и нуждаются в укрытии. В сообществе обрастания среди талломов макрофитов и переплетений биссусных нитей двустворчатых моллюсков они находят себе не только убежище, но и пищу. В этот период они активно потребляют детрит, который всегда присутствует в сообществе обрастания (Hmeleva, 1973).

Затем подросшие ракообразные переходят на другие пищевые ресурсы. Как уже упоминалось, они всеядны, но отдают предпочтение растительной пище. Здесь начинает проявляться трофическая специализация каждого вида, обусловленная особенностями функциональной морфологии их ротового аппарата. У I. balthica basteri хорошо развиты сильно хитинизированные челюсти, с помощью которых они могут отгрызать кусочки макрофитов и активно перетирать их (Naylor, 1955). У L. monodi, напротив, челюсти приспособлены к соскабливанию микрообрастаний с субстрата (Alemanno et al., 2007). Таким образом, I. balthica basteri потребляет, в основном, мягкие части талломов макрофитов, а L. monodi - эпифитные микроводоросли (Hmeleva, 1973; Alemanno et al., 2007).

К одному из элементов жизненной стратегии обоих видов можно отнести наличие у них явно выраженной покровительственной окраски наружных покровов тела. Подобная окраска является пассивным способом защиты от нападения хищников. Эти ракообразные входят в пищевой спектр некоторых видов рыб (Kvach and Zamorov, 2001). У менее подвижных L. monodi отмечена наиболее разнообразная приспособительная окраска. Темноокрашенные особи этого вида сливаются с общим фоном субстрата сообщества обрастания. Пестро окрашенные формы (с чередованием светлых и темных пятен) и особи с продольной полосой вдоль тела мало заметны на фоне мидий, покрытых различными эпифитными организмами. Красноватые особи сливаются с талломами красных водорослей родов Ceramium и Callithamnion, а экземпляры белого цвета мало заметны на фоне многочисленных домиков усоногих раков Amphibalanus improvisus (Darwin, 1854), расположенных на створках мидий. У представителей I. balthica basteri отмечены только первые три типа покровительственной окраски (Varigin, 2014b).

Разнообразие жизненных стратегий тесно связано с концепцией экологической ниши, поскольку значительная часть характерных особенностей ниши - это и есть элементы жизненной стратегии. Индивидуальность экологической ниши вида определяется оригинальностью в данных условиях его конкретной жизненной стратегии (Protasov, 2009). Как следует из вышеизложенного, перекрывание экологических ниш двух изучаемых видов ракообразных происходит лишь по местообитанию. Действительно, они обитают совместно в условиях сообщества обрастания Одесского залива. Однако размеры этих видов, так же как их количество, несопоставимы с масштабами этого сообщества, которое развивается на подводной поверхности берегозащитных гидротехнических сооружений, расположенных в прибрежной зоне моря у берегов Одессы. Таким образом, топическая конкуренция между этими видами в данном случае значительно ослаблена.

Трофическая конкуренция между ними также незначительна ввиду различий по пищевой специализации. Периоды массовой репродукции в течение года у этих видов разнесены по времени (табл.). Особенности репродукционных процессов обоих видов отражаются на годовой динамике их биомассы в изучаемом сообществе (рис.).

Наибольшая биомасса у I. balthica basteri отмечена в зимний период, когда в популяции присутствуют, в основном, крупные взрослые особи, а также ранней весной, когда они приступают к размножению (рис.). Затем в летний период биомасса этих ракообразных резко падает ввиду их массовой гибели после завершения процесса репродукции. В то же время у особей L. monodi прослеживается обратная тенденция: максимальная биомасса у них отмечена в летние месяцы, когда происходит процесс массового размножения (рис.).

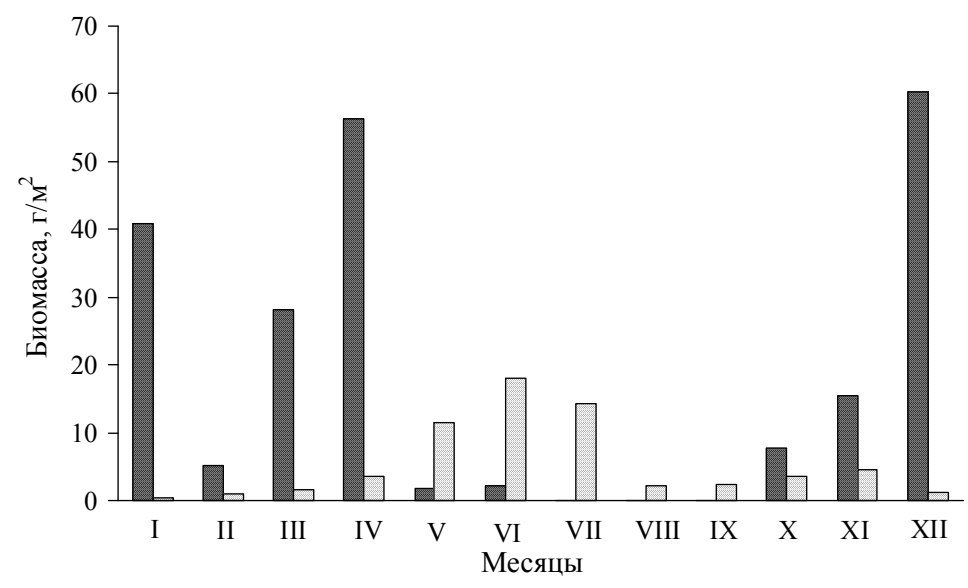

Рис. Годовая динамика биомассы Idotea balthica (темная штриховка) и Lekanesphaera monodi (светлая штриховка) в сообществе обрастания Одесского залива Черного моря

Массовые миграции из прибрежной зоны у этих видов происходят в разные сезоны года, что также отражается на динамике их биомассы. Особи I. balthica basteri в конце лета - начале осени при повышении температуры воды до $25^{\circ} \mathrm{C}$, стремясь избежать перегрева, мигрируют из прибрежной зоны моря в глубинные, менее прогре- 
тые слои воды. В этот период их биомасса достигает минимальных значений (рис.). A L. monodi, как более теплолюбивый вид, наоборот, покидает прибрежную зону зимой, мигрируя в глубинные слои воды, менее подверженные охлаждению. Таким образом, конкуренция по оси времени между этими видами также ослаблена.

Конкурентные отношения в природных условиях носят в основном диффузный характер, отражающий относительно слабые по силе взаимодействия между большинством видов сообщества (Pianka, 1981; Burkovskij, 1992). Сильная межвидовая конкуренция относится к редким природным явлениям. Она возможна только между экологически близкими видами и при условии острого дефицита пищи или предельно высокой плотности организмов. В действительности обычно наблюдается сосуществование потенциальных конкурентов, при котором каждый вид достигает сбалансированной по отношению к другим членам сообщества плотности (Burkovskij, 2006).

В природных условиях существование среди видов обособленных r- и К-стратегов весьма условно. Каждый из организмов в разные периоды своей жизни использует сложную комбинацию из элементов обеих стратегий (Rozenberg and Rjanskij, 2005). Рассматриваемые виды ракообразных по уровню защищенности от влияния абиотических факторов среды, степени заботы о потомстве и активности в потреблении ресурсов проявляют сходство с К-стратегами. Однако наличие короткого жизненного цикла (продолжительность жизни обоих видов составляет около года), а также быстрое достижение особями половой зрелости сближают их с r-стратегами.

Эффективность той или иной жизненной стратегии определяется ее конечным результатом: присутствием популяции данного вида в сообществе (Protasov, 2009). В данном случае жизненные стратегии I. balthica basteri и L. monodi оказались достаточно эффективными, так как оба вида получили массовое развитие в сообществе обрастания Одесского залива. В отдельные сезоны года численность I. balthica basteri достигала 4025 экз./м², а биомасса $-60,3 \mathrm{r} / \mathrm{m}^{2}$. При этом количественные показатели L. monodi были почти в три раза ниже (табл.).

\section{Выводы}

Высокая степень эврибионтности позволяет I. balthica basteri и L. monodi успешно противостоять воздействию абиотических факторов среды, которые в прибрежном сообществе обрастания Одесского залива Черного моря подвержены периодическим и весьма значительным колебаниям. Межвидовые отношения этих ракообразных внутри сообщества выявились в достаточной степени сбалансированными. Их экологические ниши перекрывались лишь по оси местообитания. При этом топические конкурентные отношения между изучаемыми видами были ослаблены. Трофическая конкуренция между ними была незначительной за счет четкой избирательности в выборе пищевых объектов. Все их основные элементы жизненного цикла, связанные с периодами массового размножения, а также миграций из прибрежной зоны моря были разнесены во времени. Жизненные стратегии I. balthica basteri и L. monodi ока- зались достаточно эффективными, что подтверждается их массовым развитием в сообществе обрастания Одесского залива.

\section{Библиографические ссылки}

Alemanno, S., Mancinelli, G., Basset, A., 2007. Detritus processing in tri-trophic food chains: A modelling approach. Int. Rev. Hydrobiol. 92(2), 103-116.

Burkovskij, I.V., 1992. Strukturno-funkcional'naja organizacija i ustojchivost' morskih donnyh soobshhestv [Structural and functional organization and stability of marine benthic communities]. MGU, Moscow (in Russian).

Burkovskij, I.V., 2006. Morskaja biogeocenologija. Organizacija soobshhestv i jekosistem [Marine biogeocenology. Organization of communities and ecosystems]. KMK, Moscow (in Russian).

Giljarov, A.M., 1990. Populjacionnaja jekologija [Population ecology]. MGU, Moscow (in Russian).

Hmeleva, N.N., 1973. Biologija i jenergeticheskij balans morskih ravnonogih rakoobraznyh (Idotea baltica basteri) [Biology and energy balance of marine isopods (Idotea baltica basteri)]. Naukova Dumka, Kiev (in Russian).

Hmeleva, N.N., 1988. Zakonomernosti razmnozhenija rakoobraznyh [Regularities of crustaceans breeding]. Nauka i Tehnika, Minsk (in Russian).

Kirkim, F., Ozcan, T., Sezgin, M., Culha, M., Katagan, T., 2014. Marine isopods (Crustacea) of Sinop Bay (Black Sea, Turkey). J. Black Sea/Medit. Environ. 20(3), 264-269.

Kusakin, O.G., 1979. Morskie i solonovatovodnye ravnonogie rakoobraznye (Isopoda) holodnyh i umerennyh vod severnogo polusharija. Podotrjad Flabellifera [Marine and brackish isopods (Isopoda) of cold and temperate waters of the northern hemisphere. Suborder Flabellifera]. Nauka, Leningrad (in Russian).

Kusakin, O.G., 1982. Morskie i solonovatovodnye ravnonogie rakoobraznye (Isopoda) holodnyh i umerennyh vod severnogo polusharija. Chast' 2. Podotrjady Anthuridea, Microcerberidea, Valvifera i Tyloidea [Marine and brackish isopods (Isopoda) of cold and temperate waters of the northern hemisphere. Part 2. Suborder Anthuridea, Microcerberidea, Valvifera and Tyloidea]. Nauka, Leningrad (in Russian).

Kvach, Y., Zamorov, V., 2001. Feeding preferences of the round goby Neogobius melanostomus and mushroom goby Neogobius cephalagres in Odessa Bay. Oceanol. Stud. 30(3-4), 91-101.

Makkaveeva, E.B., 1974. Rost i produkcija Sphaeroma serratum Fabr. v Chernom more [Growth and production of Sphaeroma serratum Fabr. in the Black Sea]. Biol. Sea 32, 43-52 (in Russian).

Mancinelli, G., Sabetta, L., Basset, A., 2005. Short-term patch dynamics of macroinvertebrate colonization on decaying reed detritus in a Mediterranean lagoon (Lake Alimini Grande, Apulia, SE Italy). Mar. Biol. 148, 271-283.

Marzano, C., Baldacconi, R., Fianchini, A., Gravina, F., Corriero, G., 2007. Settlement seasonality and temporal changes in hard substrate macrozoobenthic communities of Lesina Lagoon (Apulia, Southern Adriatic Sea). Chemistry and Ecology 23(6), 479-491.

Marzano, C.A., Liaci, L.S., Fianchini, F., Gravina, F., Mercurio, M., Corriero, G., 2003. Distribution, persistence and change in the macrobenthos of the lagoon of Lesina (Apulia, Southern Adriatic Sea). Oceanol. Acta 26, 57-66.

Naylor, E., 1955. The diet and feeding mechanism of Idotea. J. Mar. Biol. Assoc. UK. 34, 347-355.

Pianka, E., 1981. Jevoljucionnaja jekologija [Evolutionary ecology]. Mir, Moscow (in Russian). 
Protasov, A.A., 2009. Koncepcija zhiznennyh strategij: K voprosu o znachimosti vidov $\mathrm{v}$ soobshhestvah [The concept of life strategies: The question of the importance of species in communities]. Mor. Ecol. Zhurnal 8(1), 5-16 (in Russian).

Reizopoulou, S., Simboura, N., Barbone, E., Aleffi, F., Basset, A., Nicolaidou, A., 2014. Biodiversity in transitional waters: Steeper ecotone, lower diversity. Mar. Ecol. 35, 78-84.

Rozenberg, G.S., Rjanskij, F.N., 2005. Teoreticheskaja i prikladnaja jekologija [Theoretical and practical ecology]. NPU, Nizhnevartovsk (in Russian).

Varigin, A.Y., 2014a. Sezonnaja izmenchivost' razvitija Idotea balthica basteri (Pallas, 1772) (Crustacea, Isopoda) v soobshhestve obrastanija Odesskogo zaliva Chernogo morja [Seasonal changeability of development of Idotea balthica basteri (Pallas, 1772) (Crustacea, Isopoda) in the fouling community of the Odessa Bay, Black Sea]. Mor. Ecol. Zhurnal 13(3), 13-18 (in Russian).

Varigin, A.Y., 2014b. Fenotipicheskaja plastichnost' v sootnoshenii polov u Idotea baltica basteri (Crustacea, Isopoda) v Odesskom zalive Chernogo morja [Phenotypic plasticity in the Idotea baltica basteri (Crustacea, Isopoda) sex ratio in Odessa Bay, Black Sea]. Vìsn. Dnìpropetr. Unìv. Ser. Bìol. Med. 5(1), 49-53 (in Russian).

Vetter, R.-A., Franke, H.-D., Buchholz, F., 1999. Habitat-related differences in the responses to oxygen deficiencies in Idotea baltica and Idotea emarginata (Isopoda, Crustacea). J. Exp. Mar. Biol. Ecol. 239, 259-272.

Надійшла до редколегї 14.06.2015 